\title{
Estimation of tumour volume at therapy initiation by back-extrapolating the post- therapy regression curve of tumour volume
}

Esmaeil Mehrara ${ }^{1,2^{*}}$ and Eva Forssell-Aronsson ${ }^{1,2}$

\begin{abstract}
Background: Tumour volume at therapy initiation, $V_{i}$, is rarely available in cancer patients, and the last pre-treatment tumour volume available is from previous diagnostic imaging $\left(V_{d}\right)$. Therapeutic efficacy is thus evaluated by comparing tumour volume after treatment with $V_{d}$, instead of $V_{i}$, which results in underestimation of treatment efficacy. $V_{i}$, together with $V_{d}$, can also be used for estimation of the natural growth rate of tumour valuable for, e.g., screening programs, prognostication and individualised treatment planning such as chemotherapy scheduling. The aim of this work was to study the feasibility of estimating $V_{i}$ by back-extrapolating the post-therapy regression of tumour volume, based on data from animal model.

Methods: Nude mice bearing human neuroendocrine GOT1 tumour cell line were treated with ${ }^{177}$ Lu-DOTA-TATE. Tumour volumes were measured regularly after therapy and $V_{i}$ was estimated by back-extrapolation of (a) linear and (b) exponential regression lines of the two earliest post-therapy tumour volumes and (c) the long-term exponential regression of tumour volume. The estimated $V_{i}$ values $\left(V_{\text {est }}\right)$ were compared with the measured volume of tumour at therapy initiation.
\end{abstract}

Results: The linear regression of the two earliest post-therapy tumour volumes gave the best estimate for $V_{i}\left(V_{\text {est }}=0.91\right.$ $\left.V_{i}, p<0.00001\right)$, compared with the exponential regression models either on short-term $\left(V_{\text {est }}=2.30 V_{i}, p<0.01\right)$, or long-term ( $V_{\text {est }}=0.93 V_{i}$, non-significant) follow up of tumour volume after therapy.

Conclusion: Back-extrapolation of the early linear regression of tumour volume after therapy gave the best estimate for tumour volume at time of therapy initiation. This estimate can be used as baseline for treatment efficacy evaluation or for estimation of the natural growth rate of tumour (together with the measured tumour volume at pre-treatment diagnostic imaging).

Keywords: Tumour growth model, Regression, Linear, Exponential, GOT1, ${ }^{177}$ Lu-DOTA-TATE

\section{Background}

Knowledge of the natural growth rate of tumours is valuable for, e.g., optimization of screening programs, and individualised treatment planning, such as scheduling chemotherapy. Post-therapy suppression of tumour growth rate can also be used for early assessment of therapeutic efficacy of different therapeutic agents, e.g., cytotoxic and cytostatic therapeutics $[1,2]$.

\footnotetext{
*Correspondence: e.mehrara@radfys.gu.se

'Department of Medical Physics and Biomedical Engineering (MFT),

Sahlgrenska University Hospital, SE-41345 Gothenburg, Sweden

2Department of Radiation Physics, Institute of Clinical Sciences, Sahlgrenska

Cancer Center, Sahlgrenska Academy at the University of Gothenburg, Göteborg, Sweden
}

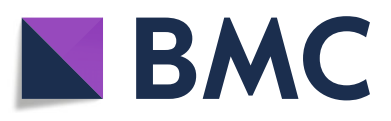

(C) The Author(s). 2018 Open Access This article is distributed under the terms of the Creative Commons Attribution 4.0 International License (http://creativecommons.org/licenses/by/4.0/), which permits unrestricted use, distribution, and

reproduction in any medium, provided you give appropriate credit to the original author(s) and the source, provide a link to the Creative Commons license, and indicate if changes were made. The Creative Commons Public Domain Dedication waiver (http://creativecommons.org/publicdomain/zero/1.0/) applies to the data made available in this article, unless otherwise stated. cific growth rate (SGR) of tumour as following $[3,4]$ :

$$
S G R=\frac{\ln \left(V_{2} / V_{1}\right)}{t_{2}-t_{1}},
$$

where $V_{1}$ and $V_{2}$ are tumour volumes at times $t=t_{1}$ and $t_{2}$, respectively. SGR is by definition equal to the limit of relative growth rate of tumour when the measurement time interval, i.e. $t_{2}-t_{1}$, approaches zero and it is usually given in $\% / d$ (percent per day). We have previously shown that SGR is mathematically and biologically a more accurate measure for tumour growth rate than the widely 
used tumour volume doubling time [3, 4]. Although the above equation is originally derived for tumour volume, it can also be used for tumour marker concentration levels for, e.g., prostate specific antigen, PSA [5], and CA125 [6]. Eq. 1 shows that estimation of tumour growth rate needs at least two tumour volume measurements before the start of therapy. In clinical practice, however, treatment is usually started as early as possible after diagnosis, not permitting the delay that a second imaging examination would be acquired. Thus, tumour volume is usually only available from one occasion, the previously performed diagnostic imaging. Mathematical methods must, therefore, be used for indirect estimation of tumour growth rate prior to treatment.

The exponential model is usually used for quantification of tumour growth rate, e.g. by SGR, but tumours may show non-exponential growth patterns, e.g. Gompertzian, if the growth is followed for a long time. However, clinical data on long term growth of tumours in untreated patients are seldom available, because the patients usually receive treatment after diagnosis and there are limited mathematical analyses that may provide methods for estimation of such non-exponential parameters of tumour growth in patients $[7,8]$. Nevertheless, growth of tumours in short term can be well described by exponential model.

In addition, knowledge of tumour volume at therapy initiation is valuable for more accurate assessment of the efficacy of treatment. A new objective method for quantification of therapeutic efficacy in cancer patients was previously proposed $[1,2]$. It was shown that neglecting the natural growth of tumour between base-line imaging and the time of therapy initiation results in underestimation of therapeutic efficacy. The method uses change in tumour volume as reference. However, in response evaluation criteria in solid tumours (RECIST), tumour size assessed by callipers can be used for efficacy assessment. Current recommendations in RECIST compare post-therapy tumour size with tumour size at diagnosis, where all baseline evaluations should be performed as close as possible to the treatment start and not more than 4 weeks before the beginning of the treatment $[9,10]$. Common human cancers can grow as fast as a few percent per day [3] and, e.g., the volume of a tumour with $\mathrm{SGR}=1 \% / \mathrm{d}$ will increase more than $30 \%$ in a 4 weeks period. Therefore, the natural growth of tumour in time period between diagnosis and therapy initiation can be considerable for fast growing tumour and can result in underestimation of therapeutic efficacy $[1,2]$.

The aim of this work was to study the feasibility of estimating tumour volume at therapy initiation by back-extrapolating the post-therapy regression of tumour volume. The study was performed using data from mice xenografted with human neuroendocrine tumours (NETs) and treated with ${ }^{177} \mathrm{Lu}$-DOTA-Tyr3-octreotate $\left({ }^{177} \mathrm{Lu}-\mathrm{DOTA}-\mathrm{TATE}\right) .{ }^{177} \mathrm{Lu}-\mathrm{DOTA}-\mathrm{TATE}$ is a somatostatin analogue and one of the most common radiopharmaceuticals used for treatment of malignant small intestine NETs that express high numbers of somatostatin receptors (SSTRs). ${ }^{177} \mathrm{Lu}$ is a medium-energy electron emitter (maximal electron energy $=498 \mathrm{keV}$, half-life $=6.6$ days) The use of this radiopharmaceutical is approved for certain groups of patients with NETs.

\section{Methods}

Data were used from a previously published article by Kölby et al. entitled "Successful receptor-mediated radiation therapy of xenografted human midgut carcinoid tumour" [11]. Nude mice bearing the human neuroendocrine GOT1 tumour cell line were i.v. treated with $30 \mathrm{MBq}(n=6), 60 \mathrm{MBq}(\mathrm{n}=6)$ or $120 \mathrm{MBq}(n=4)$ single dose of ${ }^{177}$ Lu-DOTA-Tyr3-Octreotate $\left({ }^{177}\right.$ Lu-DOTA-TATE). Tumour volumes at time of therapy initiation as well as 3, 7, 10,14 , and 21 days after therapy were measured using calipers ranged 1 to $30 \mathrm{~mm}$ in length. Tumour volume was calculated using the formula $V=4 \pi(a / 2)(b / 2)(b / 4) / 3$, where a and $b$ are the length and the width of tumour, respectively. The depth of tumour is assumed to be equal to the half of the width, i.e. $b$, in this equation, because these subcutaneous tumours grew larger in length and width compared with the depth. All tumours disappeared after treatment or started regrowth after 21 days or earlier.

All animal experiments were approved by the Ethics Committee for Animal Experiments, Gothenburg, Sweden (nr. 119-2005).

The following three models were fitted to each mouse individually and tumour volume, $\mathrm{V}_{\text {est }}$, at base-line was estimated for each mouse by back-extrapolating the best fit to the time of therapy initiation:

- Lin: Linear model was fitted to tumour volume values measured early after treatment, i.e. at days 3 and 7, and the linear regression line was backextrapolated to day 0, i.e. therapy initiation time. The TREND function in Microsoft Excel was used for calculations.

- Exp: Exponential model was fitted to tumour volume values measured early after treatment, i.e. at days 3 and 7 , and the exponential regression equation was back-extrapolated to day 0, i.e. therapy initiation time. The GROWTH function in Microsoft Excel was used for calculations.

- EXP: Exponential model was fitted to tumour volume values after treatment and the exponential regression equation was back-extrapolated to day 0 , i.e. therapy initiation time. All data points after treatment until tumour disappeared or just before regrowth were included in calculations. The GROWTH function in Microsoft Excel was used for calculations. 
The estimated $V_{\text {est }}$ values from Lin, Exp and EXP models, were plotted versus the true measured $V_{i}$ values and the correlation and residuals were calculated and compared between the three models. All calculations and correlation studies were done using Microsoft Excel.

\section{Results}

Figure 1 shows the tumour volume at time of therapy initiation $\left(\mathrm{V}_{\mathrm{i}}\right)$ estimated using the three post-therapy tumour volume regression models: Lin: Linear regression of the first two volume measurements after therapy, Exp: Exponential regression of the first two volume measurements after therapy, and EXP: Long-term exponential regression of tumour volume after therapy using all data until tumour volume reaches the minimum.

The best fit for the Lin model was $V_{\text {est }}=0.91 V_{i}\left(R^{2}=\right.$ $0.89)$ and $\mathrm{V}_{\text {est }}=0.91 \mathrm{~V}_{\mathrm{i}}-0.004\left(\mathrm{R}^{2}=0.89\right)$ with and without forcing intercept $=0$, respectively. Correlation between the estimated and the true $\mathrm{V}_{\mathrm{i}}$ was statistically significant for Lin model $(p<0.00001)$ with and without forcing intercept $=0$ and slope of the regression line was close to the ideal model with unity value, i.e. Vest $=V_{\mathrm{i}}$.

The best fit for the Exp model was $\mathrm{V}_{\text {est }}=2.3 \mathrm{~V}_{\mathrm{i}}\left(\mathrm{R}^{2}=0.64\right)$ and $\mathrm{V}_{\text {est }}=2.22 \mathrm{~V}_{\mathrm{i}}+1.28\left(\mathrm{R}^{2}=0.64\right)$ with and without forcing intercept $=0$, respectively. Correlation between the estimated and the true $V_{i}$ was statistically significant for

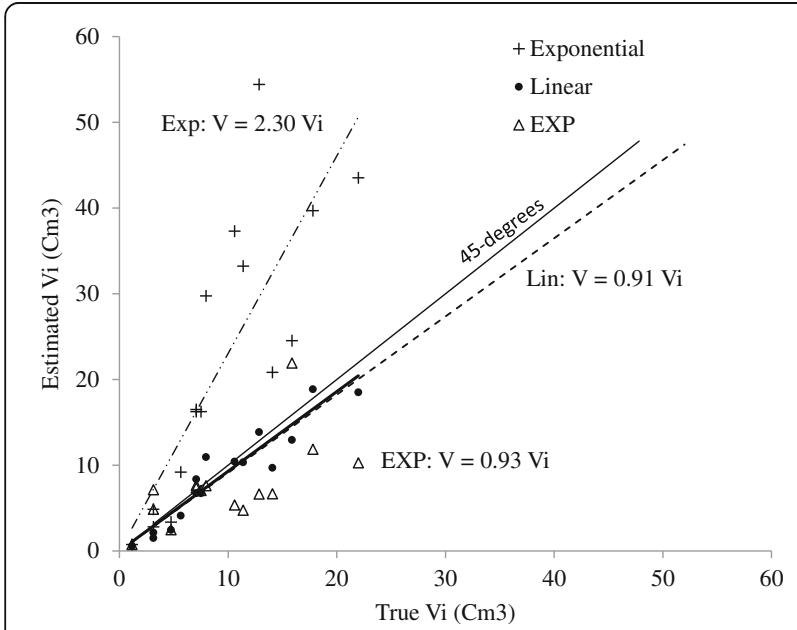

Fig. 1 Estimated tumour volume at time of therapy initiation $\left(V_{\text {est }}\right)$ calculated using three different post-therapy tumour volume regression models versus true tumour volume at time of therapy initiation $\left(V_{i}\right)$. The regression models were: Lin: Linear regression of the first two volume measurements after therapy, Exp: Exponential regression of the first two volume measurements after therapy, and EXP: Long-term exponential regression of tumour volume after therapy using all data until tumour volume reaches the minimum. Regression equations (intercept $=0$ ): Lin: $V=0.91 \mathrm{Vi},(p<0.00001) ; \operatorname{Exp}: \mathrm{V}=2.30 \mathrm{Vi},(p<0.01) ; \operatorname{EXP}: \mathrm{V}=0.93 \mathrm{~V}_{\mathrm{i}}$ (non-significant). For the EXP model, the regression equation was $V_{\text {est }}=0.7 V_{i}$, when an outlier point $\left(V_{\text {est }}=83.2, V_{i}=5.7\right)$, which is not shown in this figure, was excluded and $R^{2}=0.4$ and was the correlation was still non-significant
Exp model $(p<0.001)$ with and without forcing intercept $=0$. However, this model overestimated $V_{i}$ by a factor of 2.3 and 2.22 with and without forcing intercept $=0$, respectively.

The EXP model extremely overestimated the $V_{i}$ by a factor of more than 14 in one mouse, where $V_{\text {est }}=83.2$ and $V_{i}=5.7$. This point was considered as an outlier and was excluded from calculations and is not shown in Fig. 1. The best fit for the EXP model was then $\mathrm{V}_{\text {est }}=0.7 \mathrm{~V}_{\mathrm{i}}$ $\left(R^{2}=0.4\right)$ and $V_{\text {est }}=0.54 \mathrm{~V}_{\mathrm{i}}-2.04\left(\mathrm{R}^{2}=0.4\right)$ with and without forcing intercept $=0$, respectively. However, the best fit for the EXP model, including the outlier point, was $\mathrm{V}_{\text {est }}=$ $0.93 \mathrm{~V}_{\mathrm{i}}\left(\mathrm{R}^{2}=-0.123\right)$ and $\mathrm{V}_{\mathrm{est}}=-0.08 \mathrm{~V}_{\mathrm{i}}-13\left(\mathrm{R}^{2}=0.0006\right)$ with and without forcing intercept $=0$, respectively. The negative $R^{2}=-0.123$ obtained by the Excel program was assumed to be zero. Correlation between the estimated and the true $\mathrm{V}_{\mathrm{i}}$ was not statistically significant for the EXP model either with or without forcing intercept $=0$ for both including and excluding the outlier point $\left(\mathrm{V}_{\mathrm{est}}=83.2\right.$, $\mathrm{V}_{\mathrm{i}}=5.7$ ).

Figure 2 shows the residuals, i.e., the difference between the estimated and the true values of tumour volume at time of therapy initiation $\left(\mathrm{V}_{\mathrm{i}}\right)$ for regression models in Fig. 1. Residual sum of squares (RSS) were 66, 4718, 6416 for the Lin, Exp, and EXP models, respectively.

These results show that back-extrapolation of the early linear regression equation of tumour volume after therapy, i.e. the Lin model, gives the best estimate for tumour volume at therapy initiation.

\section{Discussion}

In this article, we studied the feasibility of estimating tumour volume at time of therapy initiation $\left(\mathrm{V}_{\mathrm{i}}\right)$ by back-extrapolating the post-therapy regression equation

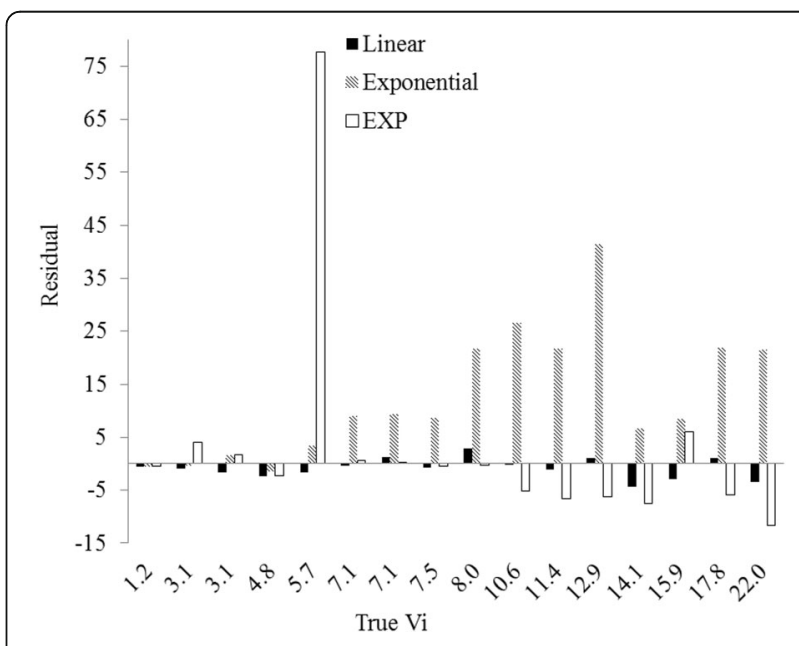

Fig. 2 Residuals, i.e., the difference between the estimated $\left(V_{\text {est }}\right)$ and the true values of tumour volume at time of therapy initiation $\left(V_{i}\right)$ for regression models in Fig. 1. Residual sum of squares (RSS): Lin: 66; Exp: 4718; EXP: 6416 
of tumour volume. $\mathrm{V}_{\mathrm{i}}$ is rarely available in patients, and the last pre-treatment measurement of tumour volume is available from previous diagnostic imaging $\left(\mathrm{V}_{\mathrm{d}}\right)$. Therapeutic efficacy is therefore evaluated by comparing the post-therapy tumour volume/size with $\mathrm{V}_{\mathrm{d}}$, instead of $\mathrm{V}_{\mathrm{i}}$, which can result in underestimation of the efficacy of treatment [1, 2]. In addition, estimation of the natural growth rate of untreated tumour needs at least two tumour volume estimations prior to therapy, e.g., $V_{d}$ and $\mathrm{V}_{\mathrm{i}}$. Furthermore, natural tumour growth rate is correlated with kinetic index [12] and patient survival [13, 14] and is also valuable for evaluating therapeutic efficacy $[1,2,6,15-21]$. Due to limited availability of diagnostic imaging, an examination close to treatment initiation is in general not possible, and indirect methods for estimation of $V_{i}$ must therefore be developed using, e.g., mathematical models.

We did not include calculations based on linear regression of long-term follow up of tumour volume after therapy, because the linear model can well describe tumour shrinkage only directly after therapy. The longer term change in tumour size/volume is however usually better described by non-linear models. In our data, similar to most published studies in literature, tumour shrinkage after therapy is clearly not linear in long term and a good linear fit cannot be obtained in order to estimate tumour volume at therapy initiation by back-extrapolation.

Our results showed that the linear regression equation of the two earliest post-therapy tumour volume estimations is the most reliable model for estimation of $V_{i}$, compared with the exponential regression models either in short- or long-term follow up of tumour volume after therapy. If tumour volumes $V_{1}$ and $V_{2}$ are measured at two earliest occasions after therapy, i.e., $t_{1}$ and $t_{2}$, respectively, the following equation gives the best estimate for tumour volume at therapy initiation:

$$
V_{i}=\frac{t_{2} V_{1}-t_{1} V_{2}}{t_{2}-t_{1}}
$$

Since, in this study, the first and the second post-treatment tumour volume measurements were done 3 and 7 days after therapy initiation, i.e. $t_{1}=3$ and $t_{2}=7$ days, eq. 2 was rewritten as $V_{i}=\left(7 V_{1}-3 V_{2}\right) / 4$

This result might seem unintuitive since in general exponential curves best describes growth curves. However, in the present application focusing on short-term behaviour, the results clearly demonstrates that although the correlation for the EXP curve was good, this model overestimated the tumour volume at time of treatment initiation by more than a factor of two. The most reliable method was then in this case the linear one. It is important to perform similar studies on other tumour types in animals and if possible humans in order to analyse if the best model is tumour type specific.

It should be noted that in clinical practice, tumour volume change after treatment may depend on many variables, including tumour size before treatment, tumour growth rate, tumour heterogeneity, drug mechanism of action, drug efficiency, treatment cycles interval, tumour resistance, clone selection/mutation and tissue perfusion. We used data from a xenograft of a well differentiated neuroendocrine tumour, that highly expresses somatostatin receptors and were submitted to a single course of treatment. These tumours may show a more uniform and linear change in size after treatment than in the clinical situation, although tumour heterogeneity is clearly present with e.g. sometimes large necrotic and hypoxic regions. It should also be noted that GOT1 tumours are slowly growing (compared with most otherwise used animal models), more in line with the clinical situation for solid tumours.

In this study, ${ }^{177} \mathrm{Lu}$-DOTA-TATE was administered as a single dose of 30,60 or $120 \mathrm{MBq}$ to each mouse. It was assumed that the different dose levels change the parameters of the post-therapy regression curve, but the regression model will be the same. In clinical situations, however, the therapeutics are almost always administered over time. This can modify the kinetics and the mathematical model of tumour regression after therapy initiation. Nevertheless, the results show that the method is promising and studies on other types of tumours and treatment modalities, especially on patient data (where true $\mathrm{V}_{\mathrm{i}}$ is available), is warranted.

In general, the tumor burden is the volume of the tumors in the body, and the tumor volume would always be the best parameter to study. Many times it is, however, too time-consuming to define the tumor volume correctly by imaging, which also must be adapted for this situation, and then a simpler way to determine tumor volume is more practical, e.g. using unidimensional measurements. It should also be mentioned that not all tumors are round or oval. In this study, we focused on a method for estimation of tumor volume at therapy initiation that can be used where such measure is needed, e.g., in our proposed method in reference 1-2. However, the general concept of the study might most probably be translatable to other measures and growth equations.

\section{Conclusion}

Back-extrapolation of the early linear regression of tumour volume after therapy gave the best estimate for tumour volume at time of therapy initiation. This estimate can be used as baseline for efficacy evaluation or (together with the measured tumour volume at pre-treatment diagnostic imaging) for estimation of the natural growth rate of tumour. 


\section{Acknowledgements}

We thank Professor Ragnar Hultborn, Dept of oncology, University of Gothenburg, for valuable discussions on oncological aspects of this study. We also thank Siv Tuneberg, Ann Wikström, Annki Illerskog, Ellinor Andersson, Gülay Altiparmak and Malin Bengtsson for their expert technical assistance in the original experiments.

This study was supported by grants from the Swedish Cancer Society, the Swedish Research Council, BioCARE - a National Strategic Research Program at University of Gothenburg, the King Gustav V Jubilee Clinic Cancer Research Foundation, the Assar Gabrielsson Cancer Research Foundation, Lions Cancerfond Väst, Gothenburg, Sweden, and governmental ALF research grants to University of Gothenburg and Sahlgrenska University Hospital.

\section{Funding}

This study was financially supported by grants from the Swedish Cancer Society, the Swedish Research Council, BioCARE - a National Strategic Research Program at University of Gothenburg, the King Gustav V Jubilee Clinic Cancer Research Foundation, the Assar Gabrielsson Cancer Research Foundation, Lions Cancerfond Väst, Gothenburg, Sweden, and governmental ALF research grants to University of Gothenburg and Sahlgrenska University Hospital.

\section{Availability of data and materials}

Please contact author for data requests.

\section{Authors' contributions}

EM conceptualized, developed and analyzed the model. EFA shared valuable insights from planning to writing and reviewing the manuscript. EM and EFA finalized the manuscript. Both authors read and approved the manuscript.

\section{Ethics approval and consent to participate}

All animal experiments were approved by the Ethics Committee for Animal Experiments, Gothenburg, Sweden (119-2005).

\section{Consent for publication}

Not applicable.

\section{Competing interests}

The authors declare that they have no competing interests.

\section{Publisher's Note}

Springer Nature remains neutral with regard to jurisdictional claims in published maps and institutional affiliations.

Received: 2 March 2018 Accepted: 10 July 2018

Published online: 07 August 2018

\section{References}

1. Mehrara E, Forssell-Aronsson E, Bernhardt P. Objective assessment of tumour response to therapy based on tumour growth kinetics. $\mathrm{Br} J$ Cancer. 2011;105:682-6.

2. Mehrara E, Forssell-Aronsson E, Bernhardt P. Objective assessment of tumour response to therapy based on tumour growth kinetics (vol 105, pg 682, 2011). Br J Cancer. 2011;105:1468.

3. Mehrara E, Forssell-Aronsson E, Ahlman H, Bernhardt P. Specific growth rate versus doubling time for quantitative characterization of tumor growth rate. Cancer Res. 2007;67:3970-5.

4. Mehrara E, Forssell-Aronsson E, Ahlman H, Bernhardt P. Quantitative analysis of tumor growth rate and changes in tumor marker level: specific growth rate versus doubling time. Acta Oncol. 2009;48:591-7.

5. Tisman G: Describing prostate Cancer dynamics: second look at PSA- doubling time and PSA-specific growth rate. 2013.

6. Colloca G, Venturino A, Addamo G, Coccorullo Z, Ratti R, Caltabiano G, Guarneri D. CA125-related measures of tumor kinetics and outcome of patients with recurrent ovarian Cancer receiving chemotherapy: a retrospective evaluation. Jpn J Clin Oncol. 2013;

7. Mehrara E, Forssell-Aronsson E. Analysis of inter-patient variations in tumour growth rate. Theor Biol Med Model. 2014;11:21.

8. Mehrara E, Forssell-Aronsson E, Johanson V, Kolby L, Hultborn R, Bernhardt P. A new method to estimate parameters of the growth model for metastatic tumours. Theor Biol Med Model. 2013;10:31
9. Eisenhauer EA, Therasse P, Bogaerts J, Schwartz LH, Sargent D, Ford R, Dancey J, Arbuck S, Gwyther S, Mooney M, et al. New response evaluation criteria in solid tumours: revised RECIST guideline (version 1.1). Eur I Cancer. 2009:45:228-47.

10. Therasse P, Arbuck SG, Eisenhauer EA, Wanders J, Kaplan RS, Rubinstein L, Verweij J, Van Glabbeke M, van Oosterom AT, Christian MC, Gwyther SG. New guidelines to evaluate the response to treatment in solid tumors. European Organization for Research and Treatment of Cancer, National Cancer Institute of the United States, National Cancer Institute of Canada. J Natl Cancer Inst. 2000;92:205-16.

11. Kolby L, Bernhardt P, Johanson V, Schmitt A, Ahlman H, Forssell-Aronsson E, Macke $\mathrm{H}$, Nilsson O. Successful receptor-mediated radiation therapy of xenografted human midqut carcinoid tumour. Br J Cancer. 2005:93:1 144-51.

12. Ferte $C$, Koscielny $S$, Albiges $L$, Rocher L, Soria JC, lacovelli R, Loriot Y, Fizazi K, Escudier B. Tumor growth rate provides useful information to evaluate sorafenib and everolimus treatment in metastatic renal cell carcinoma patients: an integrated analysis of the TARGET and RECORD phase 3 trial data. Eur Urol. 2014;65:713-20.

13. Atallah S, Cho BC, Allibhai Z, Taremi M, Giuliani M, Le LW, Brade A, Sun A, Bezjak A, Hope AJ. Impact of pretreatment tumor growth rate on outcome of early-stage lung cancer treated with stereotactic body radiation therapy. Int J Radiat Oncol Biol Phys. 2014:89:532-8.

14. Huang J, Chunta JL, Amin M, Lee DY, Grills IS, Wong CY, Yan D, Marples B, Martinez AA, Wilson GD. Detailed characterization of the early response of head-neck cancer xenografts to irradiation using (18)F-FDG-PET imaging. Int J Radiat Oncol Biol Phys. 2012:84:485-91.

15. Ingels $\mathrm{A}$, Zhao H, Thong AE, Saar M, Valta MP, Nolley R, Santos J, Peehl DM. Preclinical trial of a new dual mTOR inhibitor, MLN0128, using renal cell carcinoma tumorgrafts. Int J Cancer. 2014;134:2322-9.

16. Landowski TH, Gard J, Pond E, Pond GD, Nagle RB, Geffre CP, Cress AE. Targeting integrin alpha6 stimulates curative-type bone metastasis lesions in a xenograft model. Mol Cancer Ther. 2014;13:1558-66.

17. Lin ZY, Wu CC, Chuang YH, Chuang WL. Anti-cancer mechanisms of clinically acceptable colchicine concentrations on hepatocellular carcinoma. Life Sci. 2013:93:323-8.

18. Rizwan A, Serganova I, Khanin R, Karabeber H, Ni X, Thakur S, Zakian KL, Blasberg R, Koutcher JA. Relationships between LDH-A, lactate, and metastases in 4T1 breast tumors. Clin Cancer Res. 2013;19:5158-69.

19. Sarma HD, Das T, Banerjee S, Venkatesh M, Vidyasagar PB, Mishra KP. Biologic evaluation of a novel 188Re-labeled porphyrin in mice tumor model. Cancer Biother Radiopharm. 2010;25:47-54.

20. Bonnet M, Mishellany F, Papon J, Cayre A, Penault-Llorca F, Madelmont JC, Miot-Noirault E, Chezal JM, Moins N. Anti-melanoma efficacy of internal radionuclide therapy in relation to melanin target distribution. Pigment Cell Melanoma Res. 2010;23:e1-11.

21. Guilbert C, Annis MG, Dong Z, Siegel PM, Miller WH Jr, Mann KK. Arsenic trioxide overcomes rapamycin-induced feedback activation of AKT and ERK signaling to enhance the anti-tumor effects in breast cancer. PLoS One. 2013;8:e85995

Ready to submit your research? Choose BMC and benefit from:

- fast, convenient online submission

- thorough peer review by experienced researchers in your field

- rapid publication on acceptance

- support for research data, including large and complex data types

- gold Open Access which fosters wider collaboration and increased citations

- maximum visibility for your research: over $100 \mathrm{M}$ website views per year

At $\mathrm{BMC}$, research is always in progress.

Learn more biomedcentral.com/submissions 